\title{
Posterior reversible encephalopathy as the first manifestation of Bickerstaff's brainstem encephalitis
}

Pei-Ru Chen ${ }^{1,2}$ and Shih-Pin Chen ${ }^{1,2,3^{*}}$ (i)

\begin{abstract}
Background: Posterior reversible encephalopathy syndrome (PRES) has been associated with Guillain-Barre syndrome in rare cases. Here we report a patient in whom PRES was the presenting manifestation of Bickerstaff's brainstem encephalitis.

Case presentation: A 75-year-old woman presented with acute onset of hypertension, headache, blurred vision, and left eyelid drooping. Magnetic resonance imaging of the brain showed characteristic PRES lesions involving the parietal and occipital lobes bilaterally. On the 6th day after symptom onset, the patient developed complete ptosis and external ophthalmoplegia of both eyes, progressive ataxia, and bilateral lower limb weakness. Cerebrospinal fluid analyses revealed albuminocytological dissociation (protein: $66.6 \mathrm{mg} / \mathrm{dL}, \mathrm{WBC}: 0 / \mu \mathrm{l}$ ), and nerve conduction studies showed demyelinating sensorimotor polyneuropathy. The patient developed somnolence and a left extensor plantar response on the 8th day. A diagnosis of Bickerstaff's brainstem encephalitis was made. Treatment with plasmapheresis led to a rapid improvement of clinical symptoms. To date, only five similar cases have been reported, but this is the only case in which PRES developed prior to treatment.
\end{abstract}

Conclusions: PRES can be a comorbid condition with Bickerstaff's brainstem encephalitis, either preceding or following treatment; caution should be used in patients with either syndrome who exhibit atypical presentations.

Keywords: Bickerstaff's brainstem encephalitis, Guillain-Barre syndrome, Miller-Fisher syndrome, Posterior reversible encephalopathy syndrome

\section{Background}

Posterior reversible encephalopathy syndrome (PRES) is characterized by headache, confusion, seizures and visual loss with different triggers and associated conditions, such as acute hypertension, acute kidney injury, eclampsia, sepsis, multi-organ failure, and autoimmune disease [1]. The typical neuroimaging findings are reversible vasogenic subcortical edema involving the posterior hemispheres bilaterally. Some case reports have demonstrated the co-occurrence of Guillain-Barre syndrome (GBS) (or its spectral disorder) and PRES [2], and intravenous immunoglobulin (IVIG) has been implicated as

\footnotetext{
*Correspondence: chensp1977@gmail.com

'Department of Neurology, Neurological Institute, Taipei Veterans General Hospital, Taipei 112, Taiwan

${ }^{2}$ Faculty of Medicine, National Yang-Ming University School of Medicine,

Taipei, Taiwan

Full list of author information is available at the end of the article
}

the cause of PRES in a few cases [3-7]. The incidence of GBS in the general population is $0.75-2$ cases per 100,000 [8]. The actual incidence of PRES is unknown, but it is estimated to be rare. Therefore, the cooccurrence of both syndromes is unlikely by chance, but rather implicates a common pathogenic basis.

Here we report a patient in whom PRES was the presenting manifestation of Bickerstaff's brainstem encephalitis (BBE) and discuss the possible pathophysiological mechanisms.

\section{Case presentation}

A previously healthy 75-year-old woman complained of severe headache of the bilateral frontal area, accompanied by blurred vision and mild left eyelid ptosis for 3 days. She had upper respiratory infection symptoms (cough and sneezing) 2 weeks prior to presentation. She developed arterial hypertension $(210 / 100 \mathrm{mmHg})$ 


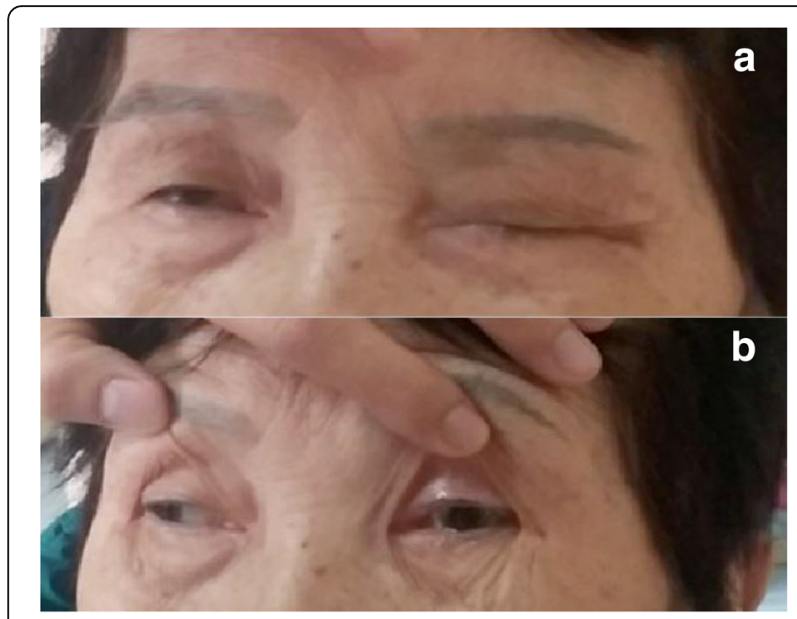

Fig. 1 Clinical pictures of our patient on the $5^{\text {th }}$ day. a bilateral ptosis. b left eye impaired adduction on right gaze

at the emergency room (on the 4th day after symptom onset). Neurological examination showed left eyelid ptosis and limited extraocular movements horizontally in the left eye with the pupil sparing (Fig. 1). There were no sympathetic signs, such as miosis and anhydrosis, nor any long tract signs. A computed tomographyangiography (CTA) excluded cerebral aneurysm or other compressive lesions of the oculomotor nerve. Brain magnetic resonance imaging (MRI) showed T2weighted hyper-intense signal abnormalities in the occipital lobes bilaterally (Fig. 2), appearing iso-intense on diffusion-weighted imaging, with an increase of the apparent diffusion coefficient, consistent with vasogenic edema. These findings were compatible with the diagnosis of PRES. Because of persistent headache and elevated systolic blood pressure, amlodipine and olmesartan were administered. However, the conditions did not improve until nimodipine, $30 \mathrm{mg} 4$ times a day, was added. On the next day, partial ptosis of the right eye developed, followed by bilateral oculomotor and trochlear nerve palsy. Generalized hyporeflexia with bilateral flexor plantar responses was noted. The Romberg test was positive. The finger-nose-finger and heel-knee-shin tests were bilaterally impaired, and an ataxic gait was present. On the 6th day, the patient experienced weakness of the lower limbs bilaterally (MRC: $3 / 5$ ) and could no longer stand. The partial ptosis of the right eyelid progressed to complete ptosis, and both eyes showed complete external ophthalmoplegia. A test for acetylcholine receptor antibody was negative. Additional laboratory studies, including erythrocyte sedimentation rate, complement factors C3 and $\mathrm{C} 4$, antinuclear antibodies, extractable nuclear antigens, antineutrophil cytoplasmic antibody, RNP, antiSSA, anti-SSB, anti-dsDNA, rheumatic factor, thyroid function, estrogen, $\mathrm{FSH}, \mathrm{LH}$, cortisol, $\mathrm{ACTH}$, prolactin, $\mathrm{HbA1C}$, hepatic, and renal function, were within normal limits. Antibodies against gangliosides (including GQ1b) were not checked because of unavailability. Cerebrospinal fluid examination demonstrated albumincytological dissociation (protein: $66.6 \mathrm{mg} / \mathrm{dl}$, white cell

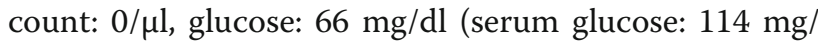
dl) and albumin: $39.69 \mathrm{mg} / \mathrm{dl}$ ) and an elevated IgG index (0.84). A panel of CSF analysis, including cytology, bacterial culture, fungal culture, and serological titers of viruses including CMV, HSV1, and HSV2, etc. all showed negative results. A nerve conduction study revealed loss of sensory nerve potentials of the bilateral sural, medial, and ulnar nerves. Motor nerve conduction studies showed demyelinating and eventually axon sensorimotor polyneuropathy (Table 1), which compatible with acquired demyelination neuropathy. Needle electromyography was unrevealing. On the 8th day, the patient had altered consciousness (Glasgow coma scale was E3V4M5) and an extensor plantar response on the left. Hypoxia, uremia, Wernicke's encephalopathy, Addison's disease, hepatic encephalopathy, and alcoholism

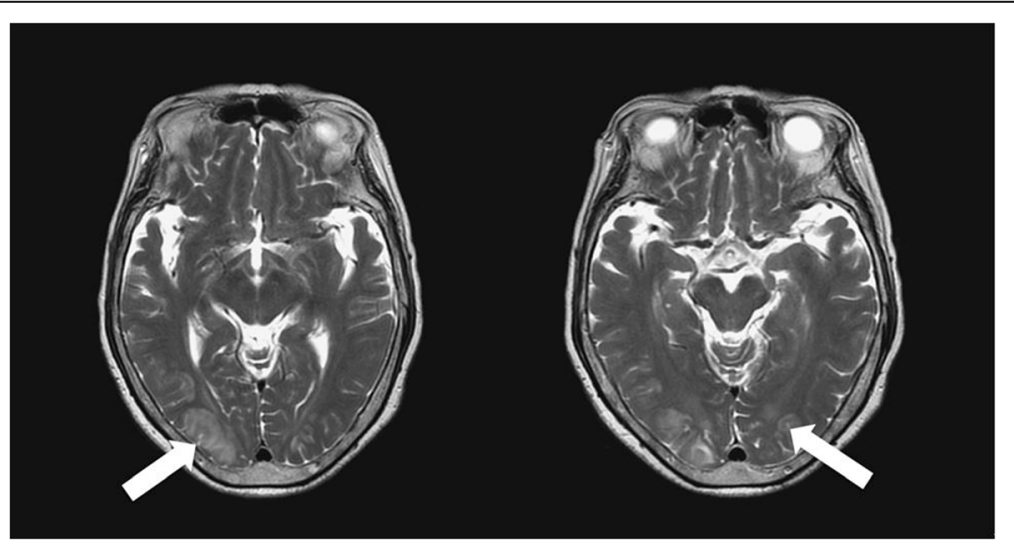

Fig. 2 Brain MRI of our patent on the $4^{\text {th }}$ day. Brain MRI T2-weighted hyper-intense signal abnormalities in the occipital lobes bilaterally 
Table 1 Motor nerve conduction study. CMAP: compound muscle action potential

\begin{tabular}{llll}
\hline Table 1. & $\begin{array}{l}\text { Distant latency } \\
(\mathrm{ms})\end{array}$ & $\begin{array}{l}\text { Conduction velocity } \\
(\mathrm{m} / \mathrm{s})\end{array}$ & $\begin{array}{l}\text { CMAP } \\
(\mathrm{mV})\end{array}$ \\
\hline L. median n. & 5.9 & 26.8 & 3.0 \\
R. median n. & $\mathrm{NA}$ & $\mathrm{NA}$ & $\mathrm{NA}$ \\
L. ulnar n. & 4.6 & 43.1 & 3.3 \\
R. ulnar n & 5.0 & 44.7 & 3.3 \\
L. peroneal n. & 6.3 & 29.9 & 2.1 \\
R. peroneal n. & 5.7 & 31.3 & 3.6 \\
L. tibial n. & 5.9 & 28.9 & 3.6 \\
R. tibial n. & 6.9 & 31.7 & 6.5 \\
\hline
\end{tabular}

were excluded on the basis of physical and laboratory findings; however, euvolemic hyponatremia (Na:119 $\mathrm{mEq} / \mathrm{L}$ ), compatible with syndrome of inappropriate antidiuretic hormone secretion (SIADH), was noted. Other co-morbidities for hyponatremia or SIADH including malignancy, intracranial infection, hemorrhage, lung disease...etc., have been excluded in our patient. A diagnosis of Bickerstaff's brainstem encephalitis with overlapping GBS and SIADH was made. Alternate day plasmapheresis was instituted for five times and the hyponatremia was gradually corrected. Her consciousness level and ophthalmoplegia improved gradually, and she could open her eyes on the 13th day. The patient received an intensive rehabilitation program and showed progressive improvement of neurological deficits. She could walk with cane and showed mild lower limb weakness (MRC: 4/5) on the 17th day. She was discharged on the 21st day with residual mild weakness and dysesthesia of the lower extremities. Two months later, she had completely recovered.

\section{Conclusions}

Our patient presented a clinical and neuroradiological pattern characteristic of PRES preceding a constellation of neurological symptoms, including complete ptosis, external ophthalmoplegia, progressive ataxia, weakness of the lower limbs bilaterally, altered consciousness, and a left extensor plantar reflex, which were consistent with Bickerstaff's brainstem encephalitis with overlapping GBS [9]. Although previous reports have suggested that PRES could be the presenting manifestation of GBS $[10,11]$ and could occur in patients with GBS variants, such as Miller-Fisher syndrome (MFS) or BBE (Table 2), our case, in contrast to most of the cases, presented with PRES as the first manifestation of BBE with overlapping GBS prior to any intervention. Three previous cases have shown the co-occurrence of MFS or MFS/ BBE-overlap syndrome and non-hypertensive PRES; however, in these cases, IVIG treatment was considered to be the culprit of PRES $[4,5,12]$. One recent case demonstrated extensive vasogenic edema in $\mathrm{BBE}$ without any intervention; however, whether the vasogenic edema of the deep white matter, brainstem, and cerebellum was attributable to PRES is uncertain [13].

The causal relationship between PRES and BBE is uncertain, but presumably is similar to that between PRES and GBS. There are some possible mechanisms that might explain the association between GBS and PRES [14]. One of them is dysautonomia. Dysautonomia is reported in $52 \%$ to two thirds of all GBS patients $[15,16]$. It can lead to a marked blood pressure surge with overwhelmed cerebrovascular auto-regulation, causing increased brain-blood capillary permeability, impaired blood-brain barrier, and eventually the development of PRES [17]. The other one is the increased level of circulating cytokines and chemokines. Pro-inflammatory

Table 2 Four cases of clinical manifestation of MFS/BBE associated with PRES

\begin{tabular}{|c|c|c|c|c|c|c|c|c|c|c|c|}
\hline \multirow{2}{*}{$\begin{array}{l}\text { Age } \\
(y / o)\end{array}$} & \multirow{2}{*}{$\begin{array}{l}\operatorname{Sex} \\
(M / F)\end{array}$} & \multicolumn{4}{|c|}{ Initial GBS (MFS/BBE) symptoms and signs } & \multirow{2}{*}{$\begin{array}{l}\text { Initial PRES } \\
\text { symptoms }\end{array}$} & \multirow[t]{2}{*}{ HTN } & \multirow[t]{2}{*}{ MRI findings } & \multirow{2}{*}{$\begin{array}{l}\text { antecedent } \\
\text { infection }\end{array}$} & \multirow{2}{*}{$\begin{array}{l}\text { IVIG } \\
\text { intervention }\end{array}$} & \\
\hline & & $\mathrm{OAA}$ & $\begin{array}{l}\text { Mental } \\
\text { disturbance }\end{array}$ & Weakness & $\begin{array}{l}\text { Plantar } \\
\text { reflex }\end{array}$ & & & & & & \\
\hline 53 & M & + & NA & - & NA & $\begin{array}{l}\text { Headache } \\
\text { ( } 4 \text { days } \\
\text { after IVIG) }\end{array}$ & $\begin{array}{l}\text { 200/130 mmHg } \\
\text { (4 days after IVIG) }\end{array}$ & $\begin{array}{l}\text { Bilateral O-P-T } \\
\text { Cerebellum } \\
\text { Basal ganglion } \\
\text { Brainstem }\end{array}$ & Yes & Yes & [4] \\
\hline 29 & $\mathrm{~F}$ & + & $\begin{array}{l}+ \\
(48 \mathrm{~h} \\
\text { after IVIG) }\end{array}$ & + & NA & $\begin{array}{l}\text { Altered } \\
\text { mental status } \\
\text { ( } 48 \mathrm{~h} \text { after IVIG) }\end{array}$ & - & $\begin{array}{l}\text { Brain stem, } \\
\text { Bilateral F-P-O }\end{array}$ & No & Yes & {$[5]$} \\
\hline 54 & $\mathrm{~F}$ & + & $\begin{array}{l}+ \\
(24-48 \text { h } \\
\text { after IVIG) }\end{array}$ & - & $\begin{array}{l}\text { bilateral } \\
\text { flexor }\end{array}$ & $\begin{array}{l}\text { Headache } \\
\text { Seizure } \\
\text { (24-48 h } \\
\text { after IVIG) }\end{array}$ & - & Bilaterally P-O & No & Yes & [10] \\
\hline $\begin{array}{l}75 \\
\text { (our } \\
\text { patient) }\end{array}$ & $\mathrm{F}$ & + & $\stackrel{+}{(\text { day } 8)}$ & $\begin{array}{l}+ \\
\text { (day 6) }\end{array}$ & $\begin{array}{l}\text { left } \\
\text { extensor }\end{array}$ & $\begin{array}{l}\text { Headache } \\
\text { Blurred vision }\end{array}$ & $\begin{array}{l}210 / 100 \mathrm{mmHg} \\
\text { (day 4) }\end{array}$ & Bilateral O & $\begin{array}{l}\text { Yes } \\
\text { URI: } 14 \text { days before } \\
\text { symptoms onset }\end{array}$ & No & \\
\hline
\end{tabular}

Abbreviations: MFS Miller-Fisher syndrome, BEE Bickerstaff brainstem encephalitis, PRES posterior reversible encephalopathy syndrome, OAA ophthalmoplegia, ataxia, and areflexia, HTN hypertension, URI upper respiratory infection, $O$ occipital lobe, $P$ parietal lobe, $T$ temporal lobe, $F$ frontal lobe 
cytokines, such as interferon- $\gamma$ and tumor necrosis factor- $\alpha$, released by $\mathrm{T}$ lymphocytes play a critical role in the pathogenesis of inflammatory demyelination of the peripheral nervous system [18]. Increased levels of chemokines, such as CCL2-CCR2, CCL5-CCR5, and CXCL10-CXCR3, have been found in GBS and experimental autoimmune neuritis in humans and animal studies, respectively $[19,20]$. These pro-inflammatory mediators may also contribute to the pathogenesis of PRES by changing capillary permeability and by enhancing the disruption of the blood-brain barrier [21].

The etiology of SIADH in our patient was uncertain, but we considered it to be comorbidity attributed to her Bickerstaff's brainstem encephalitis. SIADH has been reported in $7-48 \%$ of patients with GBS [22, 23]. The mechanism of which was hypothesized to be downward osmotic resetting and enhanced renal tubular sensitivity to antidiuretic hormone [24-26]. Of note, SIADH has been associated with poor outcome in GBS as bulbar weakness and such as the need of ventilator support or longer hospitalization period [22]. Fortunately, our patient did not run into this devastating disease cause.

To conclude, PRES could be the initial presentation of $\mathrm{BBE}$, either due to an immunological reaction against both the central and peripheral nervous systems or as a result of acute hypertension caused by autonomic dysfunction. Although the accurate rate of co-occurrence of these two syndromes remains to be explored in large-scale prospective studies, a comorbid PRES should be considered in patients with initial signs of GBS or its spectral disorders, especially in those with a blood pressure surge or visual field defect.

\section{Abbreviations}

BBE: Bickerstaff brainstem encephalitis; GBS: Guillain-Barre syndrome; IVIG: Intravenous immunoglobulin; MFS: Miller-Fisher syndrome; PRES: Posterior reversible encephalopathy syndrome; SIADH: Syndrome of inappropriate antidiuretic hormone secretion

\section{Acknowledgements}

Not applicable.

\section{Funding}

This work was supported by Taipei Veterans General Hospital (V104C-174 to S.P.C) and the Ministry of Science and Technology of Taiwan (MOST 104-2314-B-075 -006 -MY3 to S.P.C). The funders had no role in the study design, data collection and analysis, decision to publish, or preparation of the manuscript.

\section{Availability of data and materials}

The dataset supporting the conclusions of this article is included within the article.

\section{Authors' contributions}

PRC acquired and interpreted the data and drafted the manuscript; SPC is responsible for the study concept and design, and critically revised the manuscript for important intellectual content. Both authors read and approved the final manuscript.

\section{Competing interests}

The authors declare that they have no competing interests.

\section{Consent for publication}

Written informed consent was obtained from the patient for review of her records for publication. The patient consented for the publication of the report and any accompanying images. A copy of the written consent is available for review.

Ethics approval and consent to participate

The authors declare that ethics approval was not required for this case report.

\section{Author details}

'Department of Neurology, Neurological Institute, Taipei Veterans General Hospital, Taipei 112, Taiwan. ${ }^{2}$ Faculty of Medicine, National Yang-Ming University School of Medicine, Taipei, Taiwan. Inntitute of Clinical Medicine, National Yang-Ming University, Taipei, Taiwan.

Received: 16 July 2016 Accepted: 1 November 2016

Published online: 08 November 2016

\section{References}

1. Hobson EV, Craven I, Blank SC. Posterior reversible encephalopathy syndrome: a truly treatable neurologic illness. Perit Dial Int. 2012;32:590-4.

2. Chen A, Kim J, Henderson G, Berkowitz A. Posterior reversible encephalopathy syndrome in Guillain-Barre syndrome. J Clin Neurosci. 2015; 22:914-6.

3. Doss-Esper CE, Singhal AB, Smith MS, Henderson GV. Reversible posterior leukoencephalopathy, cerebral vasoconstriction, and strokes after intravenous immune globulin therapy in guillain-barre syndrome. J Neuroimaging. 2005;15:188-92.

4. Nakajima M. Posterior reversible encephalopathy complicating intravenous immunoglobulins in a patient with miller-fisher syndrome. Eur Neurol. 2005;54:58-60.

5. Stetefeld HR, Lehmann HC, Fink GR, Burghaus L. Posterior reversible encephalopathy syndrome and stroke after intravenous immunoglobulin treatment in Miller-Fisher syndrome/Bickerstaff brain stem encephalitis overlap syndrome. J Stroke Cerebrovasc Dis. 2014;23:e423-5.

6. Koichihara R, Hamano S, Yamashita S, Tanaka M. Posterior reversible encephalopathy syndrome associated with IVIG in a patient with GuillainBarre syndrome. Pediatr Neurol. 2008:39:123-5.

7. Incecik F, Herguner MO, Altunbasak S, Yildizdas D. Reversible posterior encephalopathy syndrome due to intravenous immunoglobulin in a child with Guillain-Barre syndrome. J Pediatr Neurosci. 2011;6:138-40.

8. Ropper AH. The Guillain-Barre syndrome. N Engl J Med. 1992;326:1130-6.

9. Wakerley BR, Uncini A, Yuki N, GBS Classification Group, GBS Classification Group. Guillain-Barré and Miller Fisher syndromes-new diagnostic classification. Nat Rev Neurol. 2014;10:537-44.

10. Banakar BF, Pujar GS, Bhargava A, Khichar S. Guillain-Barre syndrome with posterior reversible encephalopathy syndrome. J Neurosci Rural Pract. 2014; 5:63-5.

11. Nabi S, Rajput HM, Badshah M, Ahmed S. Posterior reversible encephalopathy syndrome (PRES) as a complication of Guillain-Barre' syndrome (GBS). BMJ Case Rep. 2016;3:2016.

12. Ribeiro BN, Salata TM, Borges RS, Marchiori E. Posterior reversible encephalopathy syndrome following immunoglobulin therapy in a patient with Miller-Fisher syndrome. Radiol Bras. 2016;49:58-9.

13. Nerrant E, Fourcade C, Coulette S, Lechiche C, Thouvenot E. Teaching Neurolmages: Extensive vasogenic edema in Bickerstaff brainstem encephalitis. Neurology. 2016;86:e38-9.

14. Rigamonti A, Basso F, Scaccabarozzi C, Lauria G. Posterior reversible encephalopathy syndrome as the initial manifestation of Guillain-Barre syndrome: case report and review of the literature. J Peripher Nerv Syst. 2012;17:356-60

15. Watson L, Aziz M, Vassallo G, Plant ND, Webb NJ. Bladder dysfunction and hypertension in children with Guillain-Barre syndrome. Pediatr Nephrol. 2014:29:1637-41.

16. Burakgazi AZ, Almahameed S. Cardiac Involvement in Peripheral Neuropathies. J Clin Neuromuscul Dis. 2016:17:120-8.

17. Schwartz RB, Feske SK, Polak JF, et al. Preeclampsia-eclampsia: clinical and neuroradiographic correlates and insights into the pathogenesis of hypertensive encephalopathy. Radiology. 2000;217:371-6. 
18. Mathey EK, Park SB, Hughes RA, et al. Chronic inflammatory demyelinating polyradiculoneuropathy: from pathology to phenotype. J Neurol Neurosurg Psychiatry. 2015;86:973-85.

19. Luster AD. Chemokines-chemotactic cytokines that mediate inflammation. N Engl J Med. 1998;338:436-45.

20. Chiang S, Ubogu EE. The role of chemokines in Guillain-Barre syndrome. Muscle Nerve. 2013;48:320-30.

21. Kieseier BC, Tani M, Mahad D, et al. Chemokines and chemokine receptors in inflammatory demyelinating neuropathies: a central role for IP-10. Brain. 2002;125:823-34

22. Saifudheen K, Jose J, Gafoor VA, Musthafa M. Guillain-Barre syndrome and SIADH. Neurology. 2011;76:701-4.

23. González-Suárez I, Sanz-Gallego I, Rodríguez De Rivera FJ, Arpa J. GuillainBarré syndrome: natural history and prognostic factors: a retrospective review of 106 cases. BMC Neurol. 2013;13:95.

24. Posner JB, Ertel NH, Kossmann RJ, Scheinberg LC. Hyponatremia in acute polyneuropathy: four cases with the syndrome of inappropriate secretion of antidiuretic hormone. Arch Neurol. 1967;17:530-41.

25. Penney MD, Murphy D, Walters G. Resetting of osmoreceptor response as cause of hyponatraemia in acute idiopathic polyneuritis. BMJ. 1979;2:1474-6.

26. Cooke CR, Latif KA, Huch KM, Wall BM. Inappropriate antidiuresis and hyponatremia with suppressible vasopressin in Guillain-Barré syndrome. Am J Nephrol. 1998;18:71-6.

\section{Submit your next manuscript to BioMed Central and we will help you at every step:}

- We accept pre-submission inquiries

- Our selector tool helps you to find the most relevant journal

- We provide round the clock customer support

- Convenient online submission

- Thorough peer review

- Inclusion in PubMed and all major indexing services

- Maximum visibility for your research

Submit your manuscript at www.biomedcentral.com/submit 